
ГАЗОВ

\author{
Уфимский государственный нефтяной технический университет, \\ кафедра нефтехимии и химической технологии \\ 450062, г. Уфа, ул. Космонавтов, 1; e-mail: rodik150195@rambler.ru
}

\author{
R. A. Shukhtuev, S. K. Churakova, T. I. Mannanov
}

\title{
RESEARCH OF EFFICIENCY AND ENERGY EXPENDITURE IN ACID GAS ABSORPTION PROCESS
}

\author{
Ufa State Petroleum Technological University \\ 1, Kosmonavtov Str., 450062,Ufa, Russia; e-mail: rodik150195@rambler.ru
}

\begin{abstract}
Аминовая очистка кислых газов от сероводорода получила широкое применение в нефтегазовой отрасли. В данной статье рассмотрены процессы абсорбции с использованием в качестве абсорбентов водных растворов моноэтаноламина и метилдиэтаноламина. Проведена оценка эффективности и сравнение энергозатрат на стадии абсорбции и десорбции при применении различных абсорбентов и типов контактных устройств (тарельчатых и перекрестноточных насадок). Показано, что замена абсорбента в совокупности с заменой контактных устройств дает возможность сократить расход абсорбента на $15 \%$ и энергозатраты на теплоподвод и теплосъем суммарно на $44 \%$.
\end{abstract}

Ключевые слова: абсорбция; аминовая очистка; кислый газ; коррозионная активность; метилдиэтаноламин; моноэтаноламин; перекрестноточная насадка; сероводород; экономия энергозатрат; энергоэффективность.

Сероводород является одной из наиболее распространенных нежелательных примесей углеводородного сырья. По причине высокой коррозионной активности это соединение необходимо удалять из сырьевого потока при превышении допустимой концентрации. Помимо проблемы коррозии аппаратуры и трубопроводов существует экологическая проблема: при ненадлежащей степени очистки серосодержащие соединения попадают в топливо, при сгорании которого образуется смесь, включающая в себя диоксид серы. В газах, отходящих с производств, также содержатся примеси сернистых соединений.

Дата поступления 14.05.18
Amine purification of acid gases has been widely used in the oil and gas industry. Aqueous solutions of alkanolamines are used for the purification of acid gases from hydrogen sulphide. The monoethanolamine solution is the most common from alkanolamines. In this article we have considered absorption processes using various absorbents: monoethanolamine and methyldiethanolamine. An efficiency evaluation and comparison of energy expenditure in the absorption and desorption stage with the use of trays and cross-flow packed bed. It is shown that the replacement of absorbent in combination with the replacement of contact devices makes it possible to reduce the consumption of absorbent by $15 \%$ and the energy consumption for heat supply and heat removal by a total of $44 \%$.

Key words: absorption; acid gas; amine purification; corrosive activity; cross-flow packed bed; energy efficiency; energy expenditure; hydrogen sulphide; methyldiethanolamine; monoethanolamine.

Наиболее распространенный и эффективный метод очистки кислого газа в настоящее время - абсорбционная очистка с использованием алканоламинов. Главной причиной широкого распространения абсорбционных методов является сохранение эффективности абсорбента при любом начальном содержании примесей в сырье. Более того, процессы с использованием растворов алканоламинов отличаются высокой степенью очистки, независимо от парциального давления кислых компонентов, и низкой абсорбцией углеводородных компонентов сырья, что гарантирует высокое качество очищенного потока и товарной серы, получаемой при регенерации абсорбента ${ }^{1,2}$. 
В России ведущее место занимает процесс очистки сероводородсодержащих газов с помощью раствора моноэтаноламина (МЭА) ${ }^{3}$. Стандартная схема состоит из одного или нескольких абсорберов, где происходит очистка $\mathrm{H}_{2} \mathrm{~S}$-содержащего газа, и десорбера, в котором происходит процесс регенерации насыщенного абсорбента.

В данной работе рассмотрена действующая схема с двумя абсорберами $(\boldsymbol{K}-\mathbf{1}, \boldsymbol{K}-\mathbf{2})$ и десорбером $(\boldsymbol{K}-\boldsymbol{3})$, которая представлена на рис. 1. Моделирование производилось в программе Unisim Design. Полученные результаты соответствуют фактическим данным.

В действующих абсорберах $\boldsymbol{\kappa}$-1 и $\boldsymbol{\kappa}$-2 имеется $28 \mathrm{~S}$-образных тарелок, а в десорбере $\boldsymbol{K}-\boldsymbol{3}-20$ клапанных тарелок.

\section{Расчетная часть (первая серия расчетов)}

В ходе моделирования действующей схемы было установлено: КПД S-образных тарелок в абсорберах $\boldsymbol{K}-\mathbf{1}$ и $\boldsymbol{K}-\mathbf{2}$ составляет 0.57; КПД клапанных тарелок колонны $\boldsymbol{K}$-3 равен 0.55 .

Для получения продукта с более высокой степенью очистки при применении тех же тарелок требуется либо большее количество массообменных аппаратов, либо значительное увеличение расхода абсорбента, что приведет к повышению энергозатрат.

В этой связи необходимо рассмотреть другие контактные устройства, которые обладают более низким перепадом давления и более высокой эффективностью. К таким контактным устройствам относится, например, перекрестноточная насадка ${ }^{4}$. Высокая эффективность насадки достигается за счет регулирования удельных паровых и жидкостных нагрузок с помощью независимого выбора сечений для прохода жидкой и паровой фаз $\mathbf{5 , 6}$.

Опыт реализации ресурсо-энергосберегающих технологий показывает, что при использовании перекрестноточных насадочных контактных устройств в процессах абсорбции значительно сокращаются удельные энергозатраты $^{7}$ и повышается степень очистки ${ }^{8}$. Так, например, на установке висбрекинга гудрона (ОАО «Саратовский НПЗ») в колонне $\boldsymbol{\kappa}-\mathbf{1 0 4}$, где осуществляется очистка газа висбрекинга раствором МЭА, была обеспечена степень очистки до содержания сероводорода $0.003 \%$ мас. ${ }^{\mathbf{9}}$. Особое внимание следует уделить технологии абсорбционной очистки, реализованной на Оренбургском ГПЗ. Здеь при реконструкции абсорбера 09Т103 установки У-09 в 4 раза улучшилась степень очистки газа от сероводорода. До реконструкции в очищенном газе содержание сероводорода составляло $0.02 \%$ мас. Замена нерегулярной насадки из колец Палля на перекрестноточные насадочные контактные устройства позволила повысить разделительную способность аппарата в 1.5 раза (с 4 теоретических тарелок до 6). В качестве абсорбента

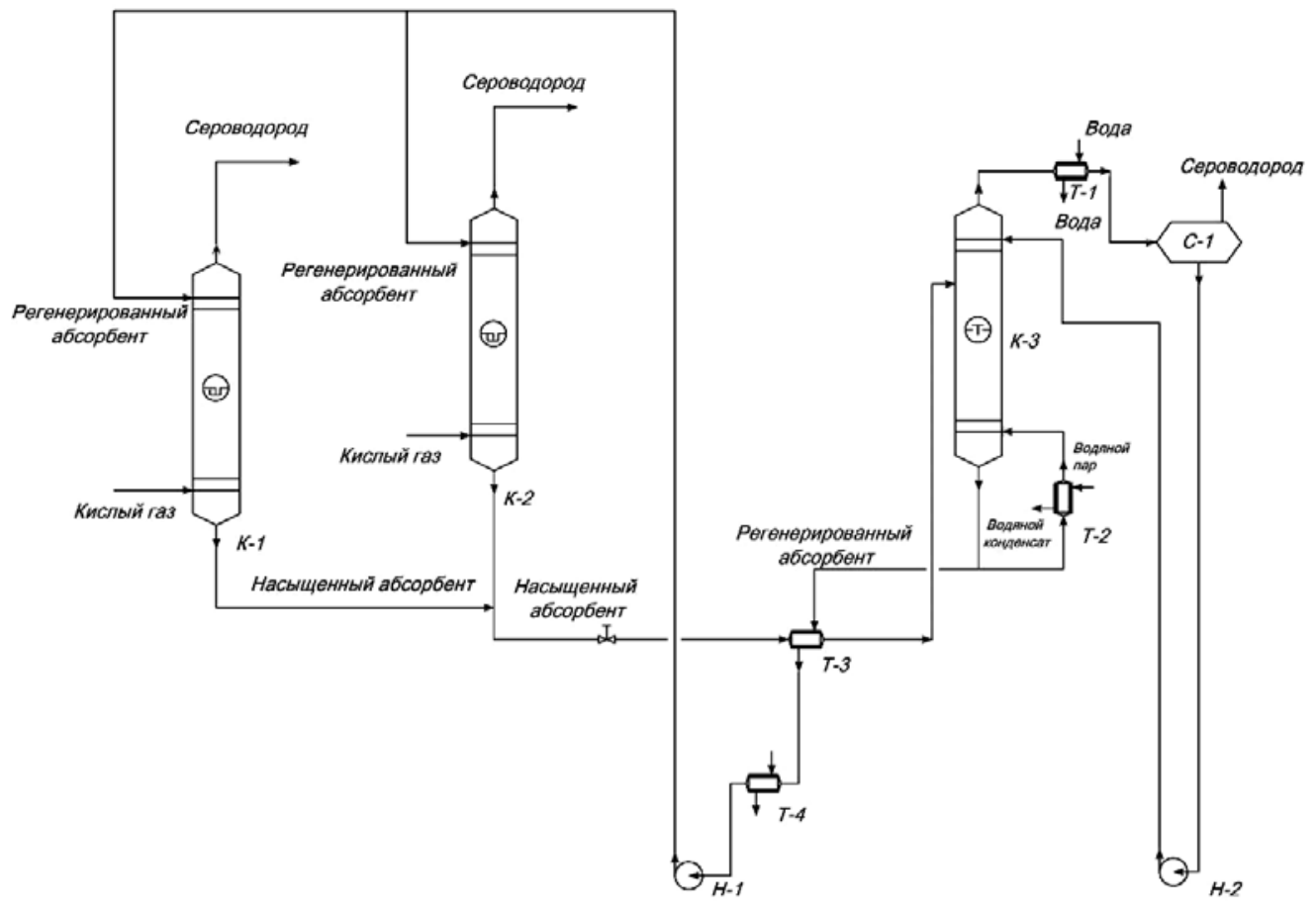

Рис. 1. Принципиальная схема блока очистки кислых газов: $K-1,2-$ абсорберы; $K-3$ - регенератор; T-1,2,3,4 - теплообменники; H-1,2 - насосы; C-1 - сепаратор. 
был использован комбинированный алканоламин, представляющий из себя водный раствор ДЭА и метилдиэтаноламина (МДЭА) ${ }^{\mathbf{8}}$.

В связи с положительным опытом реконструкции абсорбционных колонн на первом этапе расчетных исследований нами была рассмотрена замена в колоннах $\boldsymbol{K}-\mathbf{1 , 2 , 3}$ существующих тарельчатых контактных устройств на перекрестноточную насадку. Из опыта внедрения известно, что перекрестноточная насадка обладает более высоким КПД - на уровне 0.8; перепад давления на одном контактном устройстве составляет 2 мм рт. ст. ${ }^{\mathbf{1 0}, 11}$.

\section{Результаты и обсуждение (первая серия расчетов)}

Расчетный анализ показал, что вариант модернизации с заменой существующих тарелок на перекрестноточные насадочные контактные устройства (ПНКУ) обеспечит большую экономию энергозатрат при регенерации насыщенного раствора МЭА (табл. 1,2). На теплоподвод в таком варианте требуется затрачивать на $36.07 \%$ меньше энергии, чем в действующем. Теплосъем снизился на $40.60 \%$.

МЭА отличается высокой поглотительной способностью и возможностью проведения глубокой очистки при сравнительно невысоких расходах абсорбента. При этом МЭА является наименее дефицитным и наиболее дешевым по сравнению с другими аминами, хорошо обеспечивает необходимое качество очистки и приемлемую удельную производительность установки ${ }^{2}$.
Однако следует отметить, что, помимо вышеперечисленных достоинств, МЭА имеет ряд существенных недостатков, а именно ${ }^{3}$ :

- высокая коррозионная активность;

- недостаточная термическая стабильность;

- смолообразование;

- наличие интенсивного уноса абсорбента;

- большое количество теплоты, требуемое для регенерации.

В связи с этим представляет интерес рассмотрение выбора другого абсорбента.

В настоящее время имеется тенденция перевода установок аминовой очистки на менее коррозионно-активный метилдиэтаноламин (МДЭА ${ }^{2}$.

Технологическими преимуществами МДЭА являются ${ }^{2,12}$ :

- рабочая концентрация в растворе до $50 \%$ мас.;

- степень насыщения - до 0.9 моль/моль для оборудования из углеродистой стали; MЭA;

- меньшее давление паров по сравнению с

- реакция МДЭА с кислыми компонентами менее экзотермична по сравнению с другими аминами.

- срок службы абсорбента МДЭА дольше, чем МЭА, т.к. первый менее подвержен осмолению;

- переход с МЭА на МДЭА позволяет уменьшить расход на подпитку свежим абсорбентом, т.к. МДЭА менее подвержен уносу;

Таблица 1

Сравнительный анализ тарельчатого и насадочного варианта абсорберов К-1 и $K-2$

\begin{tabular}{|c|c|c|}
\hline Параметр & Действующий вариант & Вариант с насадкой \\
\hline \multicolumn{3}{|l|}{1 Температура, ${ }^{\circ} \mathrm{C}$} \\
\hline - верха $K-1, K-2$ & 46.55 & 48.28 \\
\hline - низа $K-1, K-2$ & 44.57 & 41.21 \\
\hline \multicolumn{3}{|l|}{2 Давление, кгс/см² (изб.) } \\
\hline - верха $K-1, K-2$ & 34.50 & 34.50 \\
\hline - низа $K-1, K-2$ & 34.68 & 34.57 \\
\hline - перепад по колонне $K-1, K-2$ & 0.18 & 0.07 \\
\hline \multicolumn{3}{|l|}{3 Расход, кт/4 } \\
\hline - абсорбент в $K-1, K-2$ & 10000 & 7300 \\
\hline - очищенный газ из K-1, K-2 & 5585 & 5595 \\
\hline - насыщенный абсорбент из $K-1, K$-2 & 10348 & 7638 \\
\hline \multicolumn{3}{|l|}{4 Состав газа с верха $K-1, K-2, \%$ мас. } \\
\hline - водород & 67.93 & 67.81 \\
\hline - сероводород & 0.0026 & 0.0009 \\
\hline - вода & 2.03 & 2.21 \\
\hline$-\mathrm{C}_{1}-\mathrm{C}_{4}$ & 22.33 & 22.29 \\
\hline$-\mathrm{C}_{5+}$ & 7.70 & 7.69 \\
\hline- MЭA & 0.01 & 0.01 \\
\hline \multicolumn{3}{|c|}{5 Состав насыщенного абсор бента из $K-1, K-2$, \% мас. } \\
\hline - сероводород & 4.01 & 5.34 \\
\hline - вода & 84.29 & 83.10 \\
\hline - MЭA & 11.69 & 11.56 \\
\hline
\end{tabular}


- МДЭА не присущи проблемы вспенивания раствора, зачастую ингибитор не применяется;

- моющий эффект МДЭА сильнее, чем у МЭА, а значит, имеет место тенденция к снижению коррозионных отложений;

- применение МДЭА снижает скорость коррозии аппаратуры в 2 раза по сравнению с МЭА.

\section{Расчетная часть (вторая серия расчетов)}

На второй стадии расчетных исследований нами была рассмотрена возможность замены МЭА на МДЭА. Согласно литературным данным, такая замена может обеспечить значительную экономию материальных ресурсов на очистку газа ${ }^{2}$. В ходе проведенных исследований было установлено, что снижение энергетических затрат может быть обеспечено за счет:

- уменьшения расхода циркулирующего рабочего раствора;

- увеличения степени насыщения рабочего раствора;

- снижение теплоты десорбции МДЭА.

Снижение коррозионной активности по сравнению с МЭА позволяет использовать вторичные и третичные амины в более концентрированном виде - до 50\%-ного раствора МДЭА. В ходе исследований было показано, что при этом происходит ${ }^{2}$ :

- снижение циркуляции раствора, что ведет к уменьшению использования электроэнергии на его перекачку;
- уменьшение потребления тепла, что приведет к экономии расхода энергоресурсов;

- снижение коррозии оборудования и трубопроводов уменьшит затраты на текущий ремонт;

- стабильная работа установки в период установленного межремонтного пробега приведет к улучшению условий труда обслуживающего персонала.

Результаты расчета схемы с 49\%-ным раствором МДЭА и перекрестноточными контактными устройствами представлены в табл. 3, 4.

\section{Результаты и обсуждение (вторая серия расчетов)}

Расчетный анализ показал, что вариант с заменой МЭА на МДЭА и переходом на ПНКУ позволяет экономить $87.75 \%$ энергии на теплосъеме и $73.35 \%$ - на теплоподводе. Однако при одинаковом остаточном содержании $\mathrm{H}_{2} \mathrm{~S}$ в регенерированном растворе МДЭА в 7 раз ухудшается качество очищаемого газа. Чтобы сохранить качество очищаемого газа, требуется понизить остаточное содержание сероводорода в регенерированном абсорбенте до $0.07 \%$ мас. Результаты расчета представлены в табл. 5, 6 .

Следствием понижения остаточного содержания сероводорода в регенерированном абсорбенте стало увеличение флегмового числа колонны $\boldsymbol{K}$-3 и возрастание энергетических нагрузок

Таблица 2

Сравнительный анализ тарельчатого и насадочного варианта десорбера $K$-3

\begin{tabular}{|c|c|c|}
\hline Параметр & Действующий вариант & Вариант с насадкой \\
\hline \multicolumn{3}{|l|}{1 Температура, ${ }^{\circ} \mathrm{C}$} \\
\hline - верха $K$-3 & 115.9 & 114.9 \\
\hline - низа $K-3$ & 122.7 & 120.5 \\
\hline \multicolumn{3}{|l|}{2 Давление, ктс/см ${ }^{2}$ (изб.) } \\
\hline - верха $K-3$ & 0.95 & 0.95 \\
\hline - низа $K-3$ & 1.15 & 1.00 \\
\hline - перепад по колонне $K-3$ & 0.20 & 0.05 \\
\hline \multicolumn{3}{|l|}{ З Расход, кг/ч } \\
\hline - сырьевой поток & 20696 & 15275 \\
\hline - кислый газ с верха & 793 & 793 \\
\hline - орошение & 3476 & 2060 \\
\hline - регенерированный абсорбент & 19903 & 14482 \\
\hline 4 Теплосъем $К-3$, кДж/ч & $0.899 \cdot 10^{7}$ & $0.534 \cdot 10^{7}$ \\
\hline 5 Теплоподвод К-3, кДж/ч & $1.191 \cdot 10^{7}$ & $0.762 \cdot 10^{7}$ \\
\hline \multicolumn{3}{|l|}{6 Состав газа с верха $K-3, \%$ мас. } \\
\hline - водород & 0.11 & 0.08 \\
\hline - сероводород & 98.22 (779 кг/ч) & 98.22 (779 кг/ч) \\
\hline - вода & 1.61 & 1.65 \\
\hline$-\mathrm{C}_{1}-\mathrm{C}_{4}$ & 0.05 & 0.04 \\
\hline$-\mathrm{C}_{5}+$ & 0.01 & 0.01 \\
\hline - МЭА & 0.00 & 0.00 \\
\hline $\begin{array}{l}7 \text { Остаточное содержание } \mathrm{H}_{2} \mathrm{~S} \\
\text { в регенерированном абсорбенте, \% мас. }\end{array}$ & 0.25 & 0.25 \\
\hline 8 Флегмовое число & 4.38 & 2.60 \\
\hline
\end{tabular}


Сравнительный анализ режимных параметров тарельчатыхи насадочных абсорбционных колонн K-1 и K-2 при одинаковом остаточном содержании $\mathrm{H}_{2} \mathrm{~S}$ в регенерированном абсорбенте

\begin{tabular}{|c|c|c|}
\hline Параметр & Действующий вариант (МЭА) & Насадочный вариант (МДЭА) \\
\hline \multicolumn{3}{|l|}{1 Температура, ${ }^{\circ} \mathrm{C}$} \\
\hline - верха $K-1, K-2$ & 46.54 & 42.04 \\
\hline - низа $K-1, K-2$ & 44.59 & 41.31 \\
\hline \multicolumn{3}{|l|}{2 Давление, кгс/см ${ }^{2}$ (изб.) } \\
\hline - верха $K-1, K-2$ & 34.50 & 34.50 \\
\hline - низа $K-1, K-2$ & 34.68 & 34.57 \\
\hline - перепад по колонне $K-1, K-2$ & 0.18 & 0.07 \\
\hline \multicolumn{3}{|l|}{ З Расход, кг/ч } \\
\hline - абсорбент в $K-1, K-2$ & 10000 & 8500 \\
\hline - очищенный газ из $K-1, K-2$ & 5585 & 5555 \\
\hline - насыщенный абсорбент из $K-1, K-2$ & 10348 & 8878 \\
\hline \multicolumn{3}{|l|}{4 Состав газа с верха $K-1, K-2, \%$ мас. } \\
\hline - водород & 67.93 & 68.29 \\
\hline - сероводород & 0.0026 & 0.02 \\
\hline - вода & 2.03 & 1.49 \\
\hline$-\mathrm{C}_{1}-\mathrm{C}_{4}$ & 22.33 & 22.45 \\
\hline$-\mathrm{C}_{5+}$ & 7.70 & 7.75 \\
\hline - МЭА (МДЭА) & 0.01 & 0.00 \\
\hline \multicolumn{3}{|l|}{$\begin{array}{l}5 \text { Состав насыщенного } \\
\text { абсорбента из } K-1, K-2, \% \text { мас. }\end{array}$} \\
\hline - сероводород & 4.01 & 4.60 \\
\hline - вода & 84.29 & 48.56 \\
\hline - МЭА (МДЭА) & 11.69 & 46.84 \\
\hline
\end{tabular}

Сравнительный анализ режимных параметров тарельчатого и насадочного десорбера K-3 при одинаковом остаточном содержании $\mathrm{H}_{2} \mathrm{~S}$ в регенерированном абсорбенте

\begin{tabular}{|c|c|c|}
\hline Параметр & Действующий вариант (МЭА) & Насадочный вариант (МДЭА) \\
\hline \multicolumn{3}{|l|}{1 Температура, ${ }^{\circ} \mathrm{C}$} \\
\hline - верха $K-3$ & 115.9 & 114.5 \\
\hline - низа $K-3$ & 122.7 & 121.6 \\
\hline \multicolumn{3}{|l|}{2 Давление, кгс/см² (изб.) } \\
\hline - верха $K-3$ & 0.95 & 0.90 \\
\hline - низа $K-3$ & 1.15 & 0.95 \\
\hline - перепад по колонне $K-3$ & 0.20 & 0.05 \\
\hline \multicolumn{3}{|l|}{3 Расход, кг/ч } \\
\hline - сырьевой поток & 20696 & 17756 \\
\hline - кислый газ с верха & 793 & 793 \\
\hline - орошение & 3476 & 419 \\
\hline - регенерированный абсорбент & 19903 & 16963 \\
\hline 4 Теплосъем $K-3$, кДж/ч & $0.899 \cdot 10^{7}$ & $0.110 \cdot 10^{7}$ \\
\hline 5 Теплоподвод $K-3$, кДж/ч & $1.191 \cdot 10^{7}$ & $0.317 \cdot 10^{7}$ \\
\hline \multicolumn{3}{|l|}{6 Состав газа с верха $K-3, \%$ мас. } \\
\hline - водород & 0.11 & 0.06 \\
\hline - сероводород & 98.22 (779 кг/ч) & 97.60 (773 кг/ч) \\
\hline - вода & 1.61 & 2.31 \\
\hline$-\mathrm{C}_{1}-\mathrm{C}_{4}$ & 0.05 & 0.03 \\
\hline$-\mathrm{C}_{5+}$ & 0.01 & 0.00 \\
\hline$-\mathrm{M} Э \mathrm{~A}$ & 0.00 & 0.00 \\
\hline $\begin{array}{l}7 \text { Остаточное содержание } \mathrm{H}_{2} \mathrm{~S} \text { в регене- } \\
\text { рированном абсорбенте, \% мас. }\end{array}$ & 0.25 & 0.25 \\
\hline 8 Флегмовое число & 4.38 & 0.52 \\
\hline
\end{tabular}

при тех же сырьевых нагрузках по сравнению с вариантом в табл. 6. В данном варианте экономия энергозатрат по сравнению с действующим вариантом составила: $22.74 \%$ на теплосъем, 22.12\% - на теплоподвод за счет снижения перепада давления и сниже- ния расхода абсорбента, подаваемого на регенерацию в десорбер, на 15\%.

Таким образом, замена абсорбента МЭА на МДЭА и контактных устройств при условии сохранения качества очищаемого газа позволяет повысить энергоэффективность процесса очист- 
Сравнительный анализ режимных параметров тарельчатых и насадочных абсорбционных колонн К-1 и К-2 при условии сохранения качества очищенного газа

\begin{tabular}{|c|c|c|}
\hline Параметр & Действующий вариант (МЭА) & Насадочный вариант (МДЭА) \\
\hline \multicolumn{3}{|l|}{1 Температура, ${ }^{\circ} \mathrm{C}$} \\
\hline - верха $K-1, K-2$ & 46.54 & 41.96 \\
\hline - низа $K-1, K-2$ & 44.59 & 41.50 \\
\hline \multicolumn{3}{|l|}{2 Давление, кгс/см² (изб.) } \\
\hline - верха $K-1, K-2$ & 34.50 & 34.50 \\
\hline - низа $K-1, K-2$ & 34.68 & 34.57 \\
\hline - перепад по колонне $K-1, K-2$ & 0.18 & 0.07 \\
\hline \multicolumn{3}{|l|}{ З Расход, кг/ч } \\
\hline - абсорбент в $K-1, K-2$ & 10000 & 8500 \\
\hline - очищенный газ из $K-1, K-2$ & 5585 & 5554 \\
\hline - насыщенный абсорбент из $K-1, K-2$ & 10348 & 8879 \\
\hline \multicolumn{3}{|l|}{4 Состав газа с верха $K-1, K-2, \%$ мас. } \\
\hline - водород & 67.93 & 68.32 \\
\hline - сероводород & 0.0026 & 0.0026 \\
\hline - вода & 2.03 & 1.48 \\
\hline$-\mathrm{C}_{1}-\mathrm{C}_{4}$ & 22.33 & 22.45 \\
\hline$-\mathrm{C}_{5}+$ & 7.70 & 7.75 \\
\hline - МЭА (МДЭА) & 0.01 & 0.00 \\
\hline \multicolumn{3}{|l|}{$\begin{array}{l}5 \text { Состав насыщенного абсорбента } \\
\text { из } K-1, K-2, \% \text { мас. }\end{array}$} \\
\hline - сероводород & 4.01 & 4.46 \\
\hline - вода & 84.29 & 48.63 \\
\hline - МЭА (МДЭА) & 11.69 & 46.91 \\
\hline
\end{tabular}

Таблица 6

Сравнительный анализ режимных параметров тарельчатого и насадочного десорбера К-3 при условии сохранения качества очищенного газа

\begin{tabular}{|c|c|c|}
\hline Параметр & Действующий вариант (МЭА) & Насадочный вариант (МДЭА) \\
\hline \multicolumn{3}{|l|}{1 Температура, ${ }^{\circ} \mathrm{C}$} \\
\hline - верха $K-3$ & 115.9 & 114.5 \\
\hline - низа $K-3$ & 122.7 & 121.6 \\
\hline \multicolumn{3}{|l|}{2 Давление, кгс/см ${ }^{2}$ (изб.) } \\
\hline - верха $K-3$ & 0.95 & 0.90 \\
\hline - низа $K-3$ & 1.15 & 0.95 \\
\hline - перепад по колонне $K$-3 & 0.20 & 0.05 \\
\hline \multicolumn{3}{|l|}{3 Расход, кг/ч } \\
\hline - сырьевой поток & 20696 & 17758 \\
\hline - кислый газ с верха & 793 & 887 \\
\hline - орошение & 3476 & 2872 \\
\hline - регенерированный абсорбент & 19903 & 16871 \\
\hline 4 Теплосъем $K-3$, кДж/ч & $0.899 \cdot 10^{\prime}$ & $0.694 \cdot 10^{\prime}$ \\
\hline 5 Теплоподвод $К-3$, кДж/ч & $1.191 \cdot 10^{\prime}$ & $0.928 \cdot 10^{7}$ \\
\hline \multicolumn{3}{|l|}{6 Состав газа с верха $K-3$, \% мас. } \\
\hline - водород & 0.11 & 0.06 \\
\hline - сероводород & $98.22(779$ кг/ч) & $87.80(779$ кг/ч) \\
\hline - вода & 1.61 & 12.11 \\
\hline$-\mathrm{C}_{1}-\mathrm{C}_{4}$ & 0.05 & 0.03 \\
\hline$-\mathrm{C}_{5+}$ & 0.01 & 0.00 \\
\hline- MЭA & 0.00 & 0.00 \\
\hline $\begin{array}{l}7 \text { Остаточное содержание } \mathrm{H}_{2} \mathrm{~S} \text { в регене- } \\
\text { рированном абсорбенте, \% мас. }\end{array}$ & 0.25 & 0.07 \\
\hline 8 Флегмовое число & 4.38 & 3.24 \\
\hline
\end{tabular}

ки кислых газов на 44.86\% суммарно по теплоподводу и теплосъему, а также сократить расход абсорбента на $15 \%$.

Исключение вспенивания, снижение коррозионной активности и более сильный моющий эффект МДЭА также позволяет продлить срок службы аппаратуры и трубопроводов и дает дополнительный экономический эффект, повышающий общие техникоэкономические показатели процесса. 


\section{Литература}

1. Мазгаров А.М., Корнетова О.М. Технологии очистки попутного нефтяного газа от сероводорода.- Казань: Казан. ун-т, 2015.- 70 с.

2. Коренченко О.В., Харламова М.Д. Эффективность применения метилдиэтаноламина в процессе аминовой очистки газов // Химические науки.- 2017.- №2 (56).- С.94-98.

3. Костенко А., Банников Л., Нестеренко С. Исследование коррозионной активности растворов моноэтаноламина [Электронный ресурс] // URL: http://ena.lp.edu.ua:8080/bitstream/ ntb/13727/1/177_185-185Volume_6_1.pdf.

4. Мнушкин И.А., Комиссаров А.В., Егуткин Н.Л. Очистка газов разложения вакуумного блока установки АВТ-1 топливного производства ОАО «НХК Башнефть-У фанефтехим»// Нефтепереработка и нефтехимия.- 2015.№10.- C.46-48.

5. Чуракова С.К., Богатых К.Ф. Разработка ресурсо-энергосберегающих технологий фракционирования на основе конструктивно-технологического подхода // Технологии нефти и газа.2013. - №4.- C.8-14.

6. Чуракова С.К. Варианты интенсификации работы действующего массообменного оборудования в процессах нефтегазопереработки и нефтехимии / Нефтепереработка и нефтехимия.2013.- №5.- C.48-53.

7. Нестеров И.Д., Чуракова С.К., Богатых К.Ф. Увеличение выработки пропан-бутановой фракции на Оренбургском ГПЗ за счет замены клапанных тарелок на перекрестноточную насадку в колоннах $374 \mathrm{C} 02$ и $374 \mathrm{C} 03$ установки 2 У-370 // Баш. хим. ж.- 2009.- Т.16, №3.- С.67-70.

8. Нестеров И.Д., Богатых К.Ф., Завалишин С.А. Анализ работы насадочного абсорбера аминовой очистки газа от сероводорода и углекислого газа // Матер. Междунар. научно-практ. конф. «Нефтегазопереработка-2007».- Уфа: ГУП ИНХП РБ, 2007.- С.145-147.

9. Нестеров И.Д., Богатых К.Ф. Разработка и промышленная реализация процесса очистки газа от сероводорода в перекрестноточном насадочном абсорбере на установке висбрекинга гудрона Саратовского НПЗ // Баш. хим. ж.2008.- T.15, №1.- С.115-117

10. Пилюгин В.В., Нестеров И.Д., Чуракова С.К., Богатых К.Ф. Разработка и промышленная реализация энергосберегающей технологии частичного отбензинивания нефти в перекрестноточной насадочной колонне на установках ЭЛОУ-АВТ и ЭЛОУ-АВТ-3 ОАО «Орскнефтеоргсинтез» // Баш. хим. ж.- 2009.- Т. 16, №2.- С.43-46.

11. Богатых К.Ф., Нестеров И.Д., Чуракова С.К. Результаты промышленных испытаний перекрестноточных насадочных колонн на установке газоразделения Оренбургского ГПЗ // Актуальные проблемы технических, естественных и гуманитарных наук: Матер. Междунар. научно-технич. конф.- Уфа: Изд-во УГНТУ, 2009.- Вып.4.- С.74.

12. Феркель Е.В. Опыт внедрения МДЭА в ООО «ПО «Киришнефтеоргсинтез» [Электронный pecypc] // URL: http://sintez-oka.com/ upload/pdfs/publication10.pdf (дата обращения: 19.04.2018).

\section{References}

1. Mazgarov A.M., Kornetova O.M. Tekhnologii ochistki poputnogo neftyanogo gaza ot serovodoroda [Technologies for cleaning associated gas from hydrogen sulphide]. Kazan: Kazan University, 2015.- 70 p.

2. Korenchenko O.V., Kharlamova M.D. Effektivnost' primeneniya metildietanolamina $v$ processe aminovoy ochistki gazov [Efficacy of the use of methyldiethanolamine in the process of amine gas purification]. Khimicheskie nauki [Chemical science], 2017, no.2 (56), pp.94-98.

3. Kostenko A., Bannikov L., Nesterenko S. Issledovanie korrozionnoi aktivnosti rastvorov monoetanolamina [Investigation of the corrosive activity of monoethanolamine solutions]. URL: http://ena.lp.edu.ua:8080/bitstream/ntb/ 13727/1/177_185-185Volume_6_1.pdf.

4. Mnushkin I.A., Komissarov A.V., Egutkin N.L. Ochistka gazov razlozheniya vakuumnogo bloka ustanovki AVT-1 toplivnogo proizvodstva OAO «NHK Bashneft'-Ufaneftekhim» [Purification of gases of decomposition of the vacuum block of unit AVT-1 of fuel productionof OJSC «PCC Bashneft-Ufaneftekhim»]. Neftepererabotka $i$ neftekhimiya [Oil refining and petrochemistry], 2015, no.10, pp.46-48.

5. Churakova S.K., Bogatykh K.F. Razrabotka resurso-energosberegayushchikh tekhnologii fraktsionirovaniya na osnove konstruktivnotekhnologicheskogo podkhoda [Development of Resource and Energy Saving Fractionation Technologies Based on Construction and Technological Approach]. Tekhnologii nefti $i$ gaza [Oil and gas technology], 2013, no.4, pp.8-14.

6. Churakova S.K. Varianty intensifikatsii raboty deystvuyushchego oborudovaniya $v$ processakh neftegazopererabotki i neftekhimii [Alternatives of an intensification of work of acting masstransfer equipment in the processes of oil\&gas refining and petrochemistry]. Neftepererabotka $i$ neftekhimiya [Oil refining and petrochemistry], 2013, no.5, pp.48-53.

7. Nesterov I.D., Churakova S.K., Bogatykh K.F. Uvelichenie vyrabotki propan-butanovoy fraktsii na Orenburgskom GPZ za schet zameny klapannykh tarelok na perekrestnotochnuyu nasadku v kolonnakh $374 S 02 i 374 S 03$ ustanovki $2 U-370$ [An increase of producing of propanebutane fraction on Orenburg gas processing plant due to replacing valve tray on cross-flow packed in $374 \mathrm{C} 02$ and $374 \mathrm{C} 03$ columns of 2U-370 units]. Bashkirskii khimicheskii zhurnal [Bashkir chemical journal], 2009, vol.16, no.3, pp.67-70.

8. Nesterov I.D., Bogatyh K.F., Zavalishin S.A. Analiz raboty nasadochnogo absorbera aminovoy ochistki gaza ot serovodoroda i uglekislogo gaza [Analysis of the operation of the packing absorber of amine gas purification from hydrogen sulphide and carbon dioxide]. Mater. Mezhdunar. nauchno-prakt. konf. «Neftegazopererabotka2007» [Proc. Int. sci. conf. «Oil and gas processing-2007»]. Ufa, GUP INKhP RB Publ., 2007, pp.145-147. 
9. Nesterov I.D., Bogatykh K.F. Razrabotka $i$ promyshlennaya realizatsiya protsessa ochistki gaza ot serovodoroda v perekrestnotochnom nasadochnom absorbere na ustanovke visbrekinga gudrona Saratovskogo NPZ [Developmeny and industrial implementation the process of gas treating from hydrogen sulphide in a cross-flom packed absorber at the tar oil viscosity breaking unit of saratov petroleum refinery]. Bashkirskii khimicheskii zhurnal [Bashkir chemical journal], 2008, vol.15, no.1, pp.115-117.

10. Pilyugin V.V., Nesterov I.D., Churakova S.K., Bogatykh K.F. Razrabotka i promyshlennaya realizatstiya ehnergosberegayuschey tekhnologii chastichnogo otbenzinivaniya neftiv perekrestnotochnoy nasadochnoy kolonne na ustanovkakh EHLOU-AVT $i$ EHLOU-AVT-3 $O A O$ «Orsknefteorgsintez» [Development an industrial implementation of the energy saving technology of partial gasoline-conversion of petroleum in a cross-flow packing column ELOUAVT and ELOU-AVT-3 at JSC «Orsknefteorgsintez»]. Bashkirskii khimicheskii zhurnal [Bashkir chemical journal], 2009, vol.16, no.2, pp.43-46.

11. Bogatykh K.F., Nesterov I.D., Churakova S.K. Rezul'taty promyshlennykh ispytaniy perekrestnotochnykh nasadochnykh kolonn na ustanovke gazorazdeleniya Orenburgskogo GPZ [Results of industrial tests of cross-flow packed columns on the gas separation unit of Orenburg GPP]. Aktual'nye problemy tekhnicheskih, estestvennyh $i$ gumanitarnyh nauk: Mater. Mezhdunar. nauchno-tekhn. konf. [Actual problems of technical, natural and human sciences: Proc. Int. sci.-techn. conf.]. Ufa, USPTU Publ., 2009, is.4, p.74.

12. Ferkel' E.V. Opyt vnedreniya MDEA $v$ OOO «PO «Kirishnefteorgsintez» [Experience in the introduction of MDEA in LLC «PO Kirishnefteorgsintez»]// URL: http://sintezoka.com/upload/pdfs/publication10.pdf. 